Gut, 1986, 27, 934-941

\title{
HLA-A and -B antigens in inflammatory bowel disease
}

\author{
I BIEMOND, W R BURNHAM, J D'AMARO, AND M J S LANGMAN
}

From the Department of Gastroenterology, Department of Immunogenetics, University Hospital, Leiden, The Netherlands, and University Department of Therapeutics, Queen's Medical Centre, Nottingham

SUMmARY We examined all available data on HLA-A and -B antigen distributions in patients with Crohn's disease and ulcerative colitis. The risk of Crohn's disease was significantly increased in individuals with HLA-A2, having a relative risk of 1.25 , in 730 pooled Caucasoid patients compared with 10863 pooled controls, and decreased in individuals with HLA-A11, having a relative risk of 0.62 . The risk of ulcerative colitis was also significantly increased in individuals with HLA-B27 and -Bw35, having a relative risk of 1.81 and 1.41 respectively, in 560 pooled Caucasoid patients compared with 6151 pooled controls, whilst in 144 pooled Japanese patients who were compared with 442 pooled controls, the risk of colitis was increased in individuals with HLA-B5 with a relative risk of 2.79. All differences remained significant after correction for the number of antigens examined. The bases for these genetic associations are unclear.

Analysis of possible associations between individual genetic factors, such as blood groups, and disease have been hindered by two important difficulties. It has not usually been possible to derive any satisfactory hypothesis for investigation and consequentially data have been examined simply because they were available for assessment. Consequently if distributional variations were detected, no knowledge existed about a mechanism to explain them.

Secondly, multiple factors have often been examined simultaneously with a correspondingly increased likelihood that the play of chance events would throw up extreme variations. Problems have been compounded by the tendency for investigators to present the results obtained in small series of individuals without further searches to determine if concordant patterns could be obtained in other series.

These difficulties are illustrated by studies of the differential distribution of HLA antigens in healthy controls and in patients with inflammatory bowel disease. Series of patients examined have been small and appropriate corrections to take account of multiple inference within series of data have not

Address for correspondence: Professor M J S Langman, University Department of Therapeutics, Queen's Medical Centre, Nottingham, NG7 2UH.

Received for publication 13 December 1985 always been applied. It is therefore not surprising that conflicting results have been often obtained. As a result, a variety of claims of significant deviations from expected values have been made.

Statistical techniques exist which allow one to aggregate sets of data of different sizes, to carry out appropriate weighting and then to derive a single figure to express the relative risk of developing a disease. We have now applied such a technique to published data concerned with the distribution of the HLA antigens in ulcerative colitis and Crohn's disease.

\section{Methods}

DATA

Sets of published figures enumerating the numbers of individuals of different HLA-A and -B types with ulcerative colitis and Crohn's disease and their controls were collated. ${ }^{1-6}$ Sets were excluded from consideration if patients seemed to have been identified by some characteristic known to be associated with HLA status, such as the occurrence of ankylosing spondylitis, primary sclerosing cholangitis, or psoriasis, if there was doubt if the data were already subsumed within a further larger set published elsewhere, if there were no comparable set of controls, and if the absolute antigen frequency could not be derived from the publication. 
Because of the large genetic distance between the Japanese and Caucasoid population, we analysed the distribution of HLA antigens available for ulcerative colitis in both populations separately.

\section{ANTIGEN DETERMINATIONS}

To compare the antigen distributions in the different studies, we analysed the broad specificities HLAA1, 2, 3, 9, 10, 11, 28, w19 and HLA-B5, 7, 8, 12, $13,14,15$, w16, 17, 18, w21, w22, 27, w35, 37, 40. The nomenclature of these antigens has changed during the period encompassed by the studies, so we have renamed the antigens according to the equivalence tables released after the consecutive Histocompatibility Workshops in 1973,1975 and $1980^{17-19}$ (Table 1).

As the HLA-C and -DR antigens have been discovered more recently, only a few studies ${ }^{1} 3501015$ are available for analysis and we have not therefore examined these.

\section{STATISTICAL METHODS}

Tables were constructed analysing separately data for HLA-A and -B in Crohn's disease and ulcerative colitis with paired data sets for patients and controls from each reported series comparing the approximate relative risks calculated according to Woolf ${ }^{20}$ and modified as proposed by Haldane. ${ }^{21}$ This modification had the advantage that it includes rather than neglecting studies in which one of the antigens has a frequency equal to zero, and this gives a less biased estimate of the population relative risk. ${ }^{21}$

For each individual antigen, the combined relative risk, the $\chi^{2}$ of the combined risk having one degree of freedom and the $\chi^{2}$ for heterogeneity with the number of degrees of freedom equal to the

Table 1 Equivalence table on nomenclature of $H L A-A$ and $-B$ antigens

\begin{tabular}{lll}
\hline Synonym & Broad specificity & Splits \\
\hline & A 9 & A w23, w24 \\
& A 10 & A 25, 26 \\
& A w19 & A 29, w30, w31, w32, w33 \\
& B 5 & B w51, w52 \\
LND & B 12 & B w44, w45 \\
& B 15 & B w62, w63 \\
& B w16 & B w38, w39 \\
AA & B 17 & B w57, w58 \\
w5, R* & B w21 & B w49, w50 \\
TY & B w35 & B w54, w55, w56 \\
w10, BB & B 37 & \\
\hline
\end{tabular}

number of studies minus one were calculated ${ }^{20}$ To evaluate individual contributions to the $\chi^{2}$ for heterogeneity, the heterogeneity $\chi^{2}$ according to Bodmer $e t a^{22}$ was calculated.

In using the probability values corresponding to the $\chi^{2}$ for the combined risks, it is inevitable that multiple statistical inference will increase the chance of type I error, claiming a difference to be true when in fact it represents chance variation. Therefore probability values less than 0.05 have been multiplied by the number of comparisons ${ }^{23}$ - that is, the number of antigens in each segregant series. ${ }^{24}$ This correction simultaneously increases the chance of type II error, claiming that no true difference exists when there is in fact one. Whenever more than one probability value was lower than $0 \cdot 05$, the sum of all $\chi^{2} s$ of the combined risk was evaluated taking the number of antigens equal to the number of degrees of freedom, to determine whether the overall distribution of antigens in the patients differed significantly from that in the controls. ${ }^{24}$

\section{Results}

CROHN'S DISEASE IN CAUCASIANS

In total 730 patients were compared with 10863 controls (Table 2). As shown in Table 3, HLA-A2 is positively associated $\left(\chi^{2}=8.05, p_{\text {corr. }}=0.04\right.$, relative risk $=1.25$ ) and HLA-A11 is negatively associated $\left(\chi^{2}=11.27, p_{\text {corr. }}=0.007\right.$, relative risk $\left.=0.62\right)$ with Crohn's disease. The sum of all $\chi^{2} s$ for combined relative risks was large $(25.49)$ and with eight degrees of freedom, one for each of the antigens tested, significant $(p<0.01)$, but this compound statistic showed no significance when the $\chi^{2} s$ of A2 and 11 were excluded, confirming that the association of these antigens with Crohn's disease is likely to be valid. None of the individual HLA-A antigen series were significantly heterogeneous, thus the combined relative risks of $\mathrm{A} 2$ and 11 are not significantly in contradiction to the relative risks found in the individual data sets.

Examination of the data for the HLA-B antigens revealed no less than six significant associations. The combined relative risk was greater than one for the antigens B14, 15, 18, w21 and 37 , while the combined relative risk of $\mathrm{B} 8$ was less than one. By correction for the number of antigens, however, only one association - that is, B18, remained significant $\left(\chi^{2}=16 \cdot 26, p_{\text {corr. }}<0.001\right.$, relative risk $\left.=1.72\right)$. The sum of $\chi^{2} \mathrm{~s}$ for combined relative risk was significantly increased $\left(\chi^{2}=59.98, p<0 \cdot 001\right)$ and remained increased if data for B18 were removed, indicating that some of the residual differences for individual antigens which appear insignificant after correction for total antigen numbers may in fact 
Table 3 Combined analysis of relative risks of Crohn's disease according to HLA antigens in Caucasoid populations

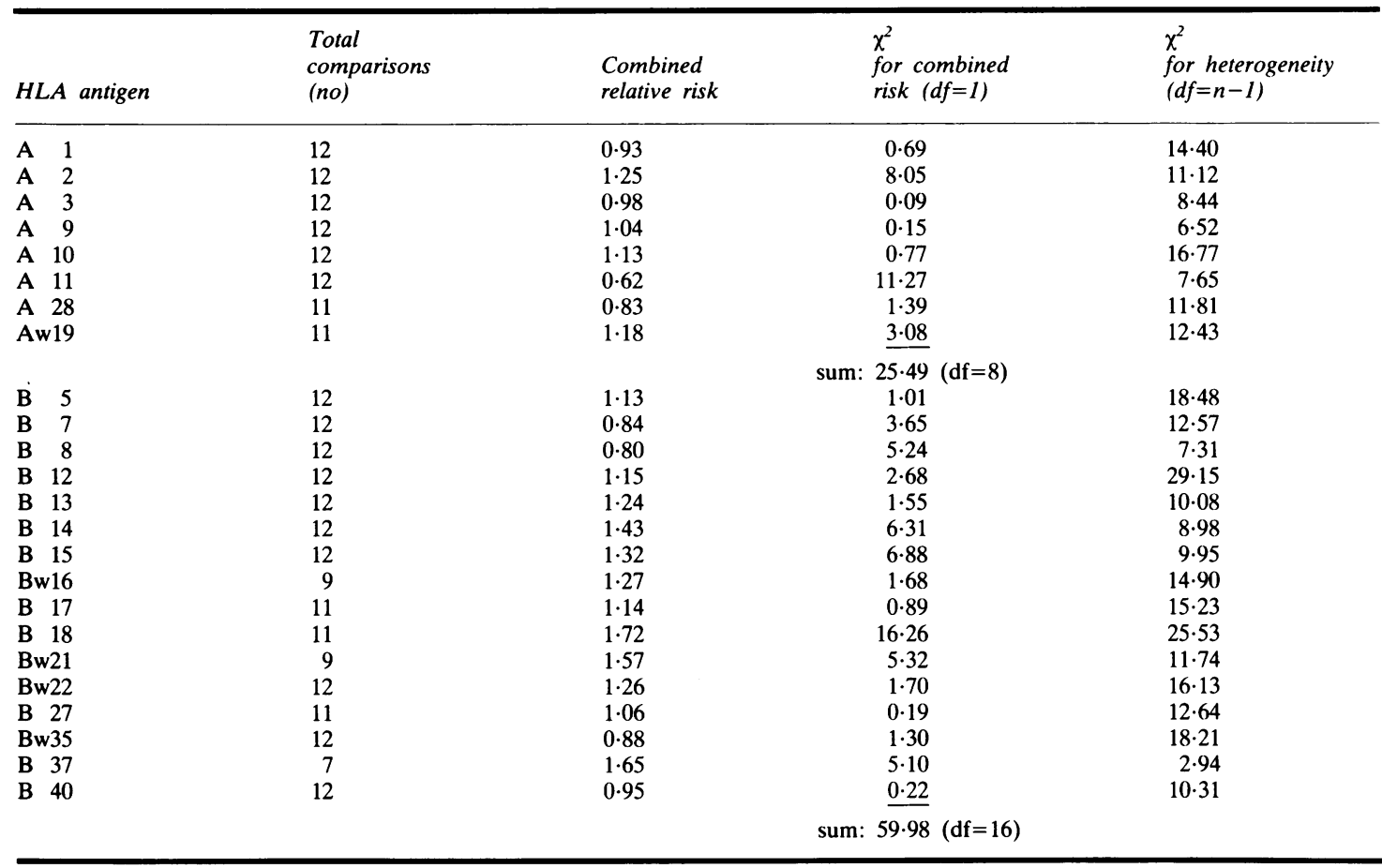

represent true associations although we are unable to tell which ones.

The $\chi^{2}$ for heterogeneity was significant for B12 and 18 , indicating great variation of relative risks between individual series. Comparing the relative risks of the individual series with the combined relative risk for B12 and 18 according to Bodmer $e t$ $a l,{ }^{22}$ we found the combined relative risk of B12 significantly different from the relative risks found in the studies in Australia, ${ }^{1}$ Sweden ${ }^{7}$ and Nottingham, UK, ${ }^{10}$ whilst the combined relative risk of B18 deviated significantly from the relative risks found in the studies in Amsterdam, ${ }^{4}$ and Birmingham. ${ }^{8}$ As the combined relative risk is the weighted mean of the individual relative risks, the individual series containing most patients and controls contributes most to the combined relative risk; so if the $\chi^{2}$ for the heterogeneity is significant another factor becomes important, namely the number of patients and controls in the individual series. As this is an uncontrolled variable, the combined relative risk says nothing in this case. Taken overall, these findings suggest that there are large unexplained variations in the distribution of HLA-B antigens in Crohn's disease from one series to another.
ULCERATIVE COLITIS IN CAUSASIANS

Five hundred and sixty patients with ulcerative colitis from Caucasoid origin were compared with 6151 healthy controls (Table 4). As shown in Table 5 none of the HLA-A antigens were found to be associated with this disease, although there was significant heterogeneity for HLA-A10, probably caused by the low frequency of this antigen in the controls in the Dutch study from Amsterdam, $\mathrm{NL}^{4}$ as compared with frequency of this antigen in the Dutch population as reported in the Histocompatibility Workshop in $1980 .^{19}$

Three HLA-B antigens, 13, 27, and w35 were found to be positively associated with ulcerative colitis, although only two were significant after correction for the number of antigens - that is, B27 $\left(\chi^{2}=16 \cdot 50, p_{\text {corr. }}=0.001\right.$, relative risk $\left.=1.81\right)$ and Bw35 $\left(\chi^{2}=9 \cdot 7, p_{\text {corr. }}=0.03\right.$, relative risk $\left.=1.41\right)$. The total sum of $\chi^{2} s$ for the combined risks was significant for 16 degrees of freedom $\left(\chi^{2}=38 \cdot 9\right.$, $\mathrm{p}<0.01$ ), but exclusion of B27 and w35 resulted in loss of significance of this statistic, suggesting that the apparent association of B13 could be the result of the play of chance. None of the HLA-B antigen results from individual centres were significantly 
HLA antigens in bowel disease

Table 5 Combined analysis of relative risks of ulcerative colitis according to HLA antigens in Caucasoid populations

\begin{tabular}{|c|c|c|c|c|}
\hline HLA antigen & $\begin{array}{l}\text { Total } \\
\text { comparisons } \\
\text { (n) }\end{array}$ & $\begin{array}{l}\text { Combined } \\
\text { relative risk }\end{array}$ & $\begin{array}{l}\chi^{2} \\
\text { for combined } \\
\text { risk }(d f=1)\end{array}$ & $\begin{array}{l}\chi^{2} \\
\text { for heterogeneity } \\
(d f=n-1)\end{array}$ \\
\hline A 1 & 11 & 1.03 & $0 \cdot 08$ & $13 \cdot 32$ \\
\hline A 2 & 11 & $1 \cdot 22$ & $4 \cdot 61$ & $9 \cdot 79$ \\
\hline A 3 & 11 & 0.97 & $0 \cdot 11$ & $4 \cdot 21$ \\
\hline A 9 & 11 & $0 \cdot 87$ & $1 \cdot 56$ & $14 \cdot 03$ \\
\hline A 10 & 11 & 1.01 & 0.00 & 22.47 \\
\hline A 11 & 11 & 1.27 & $3 \cdot 46$ & $15 \cdot 20$ \\
\hline A 28 & 10 & $1 \cdot 18$ & $1 \cdot 04$ & $12 \cdot 76$ \\
\hline \multirow[t]{2}{*}{ Aw19 } & 10 & $1 \cdot 01$ & $\underline{0 \cdot 15}$ & $16 \cdot 97$ \\
\hline & & & $11 \cdot 01(\mathrm{df}=8)$ & \\
\hline B 5 & 11 & 1.07 & 0.25 & $5 \cdot 50$ \\
\hline B 7 & 11 & 0.95 & $0 \cdot 20$ & $9 \cdot 59$ \\
\hline B 8 & 11 & $1 \cdot 10$ & $0 \cdot 77$ & $10 \cdot 88$ \\
\hline B 12 & 11 & 0.96 & $0 \cdot 16$ & $10 \cdot 05$ \\
\hline B 13 & 11 & 1.48 & $5 \cdot 26$ & $8 \cdot 34$ \\
\hline B 14 & 10 & $0 \cdot 84$ & 0.94 & $8 \cdot 87$ \\
\hline B 15 & 11 & $1 \cdot 04$ & 0.07 & $6 \cdot 51$ \\
\hline Bw16 & 8 & 0.79 & $1 \cdot 30$ & $4 \cdot 35$ \\
\hline B 17 & 10 & $0 \cdot 88$ & 0.54 & $16 \cdot 14$ \\
\hline B 18 & 10 & $1 \cdot 06$ & $0 \cdot 11$ & $12 \cdot 24$ \\
\hline Bw21 & 6 & 0.99 & 0.00 & $9 \cdot 59$ \\
\hline Bw22 & 10 & 0.90 & $0 \cdot 23$ & $9 \cdot 35$ \\
\hline B 27 & 9 & $1 \cdot 81$ & $16 \cdot 50$ & $5 \cdot 20$ \\
\hline Bw35 & 11 & 1.41 & $9 \cdot 69$ & $12 \cdot 00$ \\
\hline B 37 & 5 & 1.73 & $2 \cdot 81$ & 6.98 \\
\hline \multirow[t]{2}{*}{ B 40} & 11 & 0.96 & $\underline{0.08}$ & $13 \cdot 00$ \\
\hline & & & $38.91(\mathrm{df}=16)$ & \\
\hline
\end{tabular}

Table 6 Combined analysis of relative risks of ulcerative colitis according to HLA antigens in Japanese populations

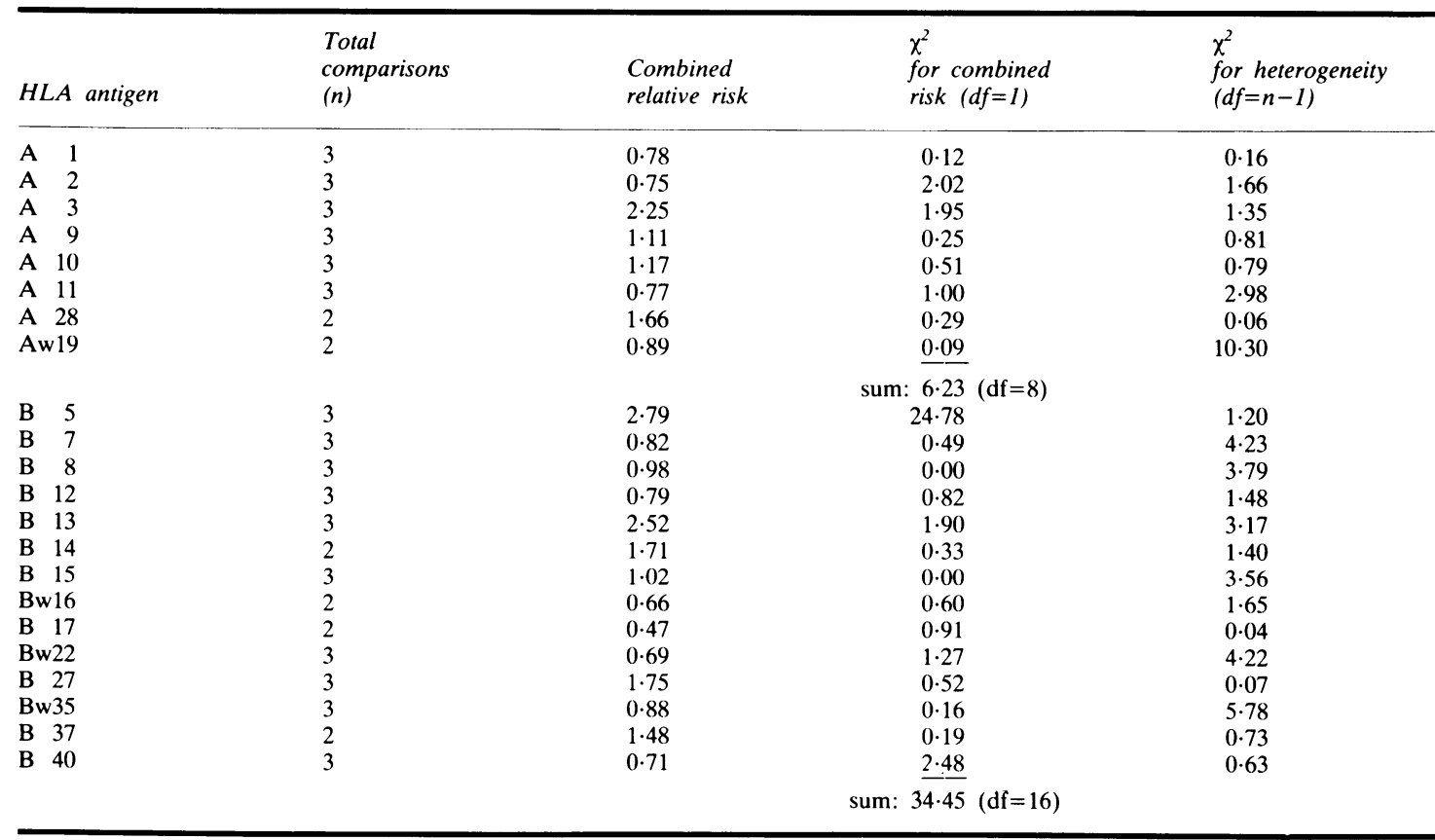


heterogeneous, indicating that findings were generally consistent.

\section{ULCERATIVE COLITIS IN JAPANESE}

One hundred and forty four Japanese patients suffering from ulcerative colitis and 442 healthy Japanese controls have been compared (Table 4). As shown in Table 6, none of the HLA-A antigens were associated with ulcerative colitis; Aw19 gave significant heterogeneity but this can be explained by the low frequency of w19 in the study of Asakura et $a^{15}$ as compared with the frequency reported in the Histocompatibility Workshop in $1980 .{ }^{19}$ The HLA-B locus showed a highly significant association with HLA-B5 $\left(\chi^{2}=24.78, \mathrm{p}_{\text {corr. }}<0 \cdot 001\right.$, relative risk $=2.79$ ) and this finding was consistent in all studies because all $\chi^{2}$ s for heterogeneity were low.

\section{Discussion}

The analysis of individual sets of data has suggested variously that liability to Crohn's disease and ulcerative colitis might be associated with a variety of antigens (Table 7). Acceptance of these findings is hindered by the small size of the individual sets of data, and generally modest levels of significance detected, sometimes in the apparent absence of corrections to take account of the multiple antigens examined and their relative distributions in test and control subjects.

After considering the results of a large number of sets of patient-control studies, we have found that Caucasians who are HLA-A11 appear to have a relative risk of about 0.62 and those who are HLAA2 a relative risk of 1.25 to develop Crohn's disease

Table 7 HLA antigens associated with inflammatory bowel disease according to literature

\begin{tabular}{lrl}
\hline & Ref & HLA antigen \\
\hline $\begin{array}{l}\text { Crohn's disease in Caucasians: } \\
\text { Austria, Vienna }\end{array}$ & 1 & B12 \\
$\begin{array}{l}\text { NL, Amsterdam } \\
\text { Sweden, Uppsala }\end{array}$ & 4 & B18 \\
UK, Manchester & 7 & B17 \\
Ulcerative colitis in Caucasians: & 9 & A3 \\
$\quad$ & & \\
Israel, Haifa & 12 & A2, Bw35, B40 \\
Israel, Tel Aviv & 6 & Bw35 \\
NL, Amsterdam & 4 & B27 \\
UK, Liverpool & 4 & B27 \\
$\quad$ UK, London & 4 & B27 \\
Ulcerative colitis in Japanese: & & \\
$\quad$ Japan, Tokyo & 14 & B5 \\
Japan, Tokyo & 15 & B5 \\
Japan, Sendai & 16 & B5 \\
\hline
\end{tabular}

(Table 3), whilst those who are HLA-B27 seem to have a relative risk of about 1.81 and those who are HLA-Bw35 a relative risk of 1.41 to suffer from ulcerative colitis (Table 5).

In Japanese quite another association was found. HLA-B5 individuals appear to have a relative risk of 2.79 to develop ulcerative colitis, while no association is found with HLA-B27 (Table 6). This last result is not surprising given that HLA-B27 is very rare in the Japanese.

We cannot easily explain these findings. HLAB27 is known to be strongly associated with liability to ankylosing spondylitis, and we might have detected an apparent association if a significant proportion of our colitic series were originally ascertained because they already had ankylosing spondylitis. In none of the series which we have examined, however, did such ascertainment seem to have occurred, and if it had been the cause of spurious association we would have expected the same to hold true for Crohn's disease, whereas the relative risk there associated with HLA-B27 was close to unity.

The mathematical techniques we have used take pairs of test and control series which are considered individually and then weighted according to their total size before an overall relative risk is calculated. Such a method clearly could not throw up a spurious overall correlation, though it could conceal a real association which was present; say in patients developing the disease in a single specific area. One check for between series variability is given by considering their heterogeneity statistically. Significant heterogeneity was detected for Crohn's disease and the cause is not clear. One possible reason could be that series were collated at different times in different places, and control data may not necessarily have been collated simultaneously. Antisera may not necessarily have been of equivalent potency, and the range available could have varied and such factors could have contributed to heterogeneity.

We conclude that an individual's HLA-A or -B status appears to influence liability to Crohn's disease and ulcerative colitis. The relative risks associated with HLA-A or -B antigens are at least as large as those associated with $\mathrm{ABO}$ blood group and secretor status, and liability to peptic ulcer and its complications. ${ }^{25}$ Evaluating the population attributable risk as measure for the rate of the disease in individuals having a certain antigen that can be attributed to that antigen, ${ }^{26}$ we found that HLA-B5 contributes $42 \%$ to ulcerative colitis in the Japanese, while in Caucasians HLA-A2 contributes no more than $11 \%$ to Crohn's disease and this figure is for the other associations even lower.

As the contribution is small, other markers within 
the HLA system should be looked for and special emphasis should be made in defining subgroups of patients to assess more fully the contribution of HLA to chronic inflammatory bowel diseases.

\section{References}

1 Smolen JS, Gangl A, Polterauer P, Menzel EJ, Mayr WR. HLA antigens in inflammatory bowel disease. Gastroenterology 1982; 82: 34-8.

2 Russell AS, Percy JS, Schlaut J et al. Transplantation antigens in Crohn's Disease. Linkage of associated ankylosing spondylitis with HL-Aw27. Dig Dis Sci 1975; 20: 359-61.

3 Cohen Z, McCulloch P, Leung MK, Mervart $H$. Histocompatibility antigens in patients with Crohn's disease. In: Pena AS, Weterman IT, Booth CC, Strobert W, eds. Recent advances in Crohn's disease. The Hague: Martinus Nijhoff, 1981: 186-91.

4 Woodrow JC, Lewkonia RM, McConnell RB, et al. HLA antigens in inflammatory bowel disease. Tissue Antigens 1978; 11: 147-52.

5 Pena AS, Biemond I, Kuiper G et al. HLA antigen distribution and HLA haplotype segregation in Crohn's disease. Tissue Antigens 1980; 16: 56-61.

6 Delpre G, Kadish U, Gazit E, Joshua H, Zamir R. HLA antigens in ulcerative colitis and Crohn's disease in Israel. Gastroenterology 1980; 78: 1452-7.

7 Bergman L, Lindblom JB, Safwenberg J, Krause U. HL-A Frequencies in Crohn's disease and ulcerative colitis. Tissue Antigens 1976; 7: 145-50.

8 Mallas EG, MacKintosh P, Asquith P, Cooke WT. Histocompatibility antigens in inflammatory bowel disease. Their clinical significance and their association with arthropathy with special reference to HLA-B27 (w27). Gut 1976; 17: 906-10.

9 Gleeson MH, Walker JS, Wentzel J, Chapman JA, Harris R. Human leucocyte antigens in Crohn's disease and ulcerative colitis. Gut 1972; 13: 438-40.

10 Burnham WR, Gelsthorpe K, Langman MJS. HLA-D related antigens in inflammatory bowel disease. In: Pena AS, Weterman IT, Booth CC, Strober W, eds. Recent advances in Crohn's disease. The Hague: Martinus Nijhoff, 1981: 192-6.
11 Eade OE, Moulton C, MacPherson BR, Andre-Ukena SST, Albertini RJ, Beeken WL. Discordant HLA haplotype segregation in familial Crohn's disease. Gastroenterology 1980; 79: 271-5.

12 Nahir M, Gideoni O, Eidelman S, Barzilai A. HLA antigens in ulcerative colitis. Lancet 1976; 2: 573.

13 Corazza GR, Tabacchi P, Calanca F, Ionata R, Barboni F, Gasbarrini G. HLA antigens and ulcerative colitis: is there any link? Ital J Gastroenterol 1978; 10: 139-41.

14 Tsuchiya M, Yoshida T, Asakura $\mathrm{H}$ et al. HLA antigens and ulcerative colitis in Japan. Digestion 1977; 15: $286-94$

15 Asakura H, Tsuchiya M, Aiso S, et al. Association of the human lymphocyte-DR2 antigen with Japanese ulcerative colitis. Gastroenterology 1982; 82: 413-8.

16 Hiwatashi N, Kikuchi T, Masamune O, Ouchi E, Watanabe $\mathrm{H}$, Goto Y. HLA antigens in inflammatory bowel disease. Tohoku J Exp Med 1980; 131: 381-5.

17 Dausset J, Colombani J. Histocompatibility testing. Copenhagen: Munksgaard, 1973.

18 Kissemeyer-Nielsen F. Histocompatibility testing. Copenhagen: Munksgaard, 1975.

19 Terasaki PI. Histocompatibility testing. Los Angeles: UCLA Tissue Typing Laboratory, 1980.

20 Woolf B. On estimating the relation between blood group and disease. Ann Hum Genet 1955; 19: 251-3.

21 Haldane JBS. The estimation and significance of the logarithm of a ratio of frequencies. Ann Hum Genet 1956; 20: 309-11.

22 Bodmer JG, Bodmer WF, Pickbourne P, Degos L, Dausset J, Dick HM. Combined analysis of three studies of patients with Burkitt's lymphoma. Tissue Antigens 1975; 5: 63-8.

23 Wiener AS. Blood groups and disease. Am J Hum Genet 1970; 22: 476-83.

24 Svejgaard A, Jersild C, Staub Nielsen L, Bodmer WF. HL-A antigens and disease. Statistical and genetical considerations. Tissue Antigens 1974; 4: 95-105.

25 McConnell RB. The genetics of gastrointestinal disorders. London: Oxford University Press, 1966.

26 Miettinen OS. Proportion of disease caused or prevented by a given exposure, trait or intervention. Am J Epidemiol 1974; 99: 325-32. 